\title{
Obtención por Y-irradiación de cepas de Saccharomyces cerevisiae tolerantes a condiciones de cultivo rigurosas, para la producción de bioetanol
}

\section{Obtention by $\mathrm{Y}$-radiation of Saccharomyces cerevisiae strains tolerant to stringent growing conditions, for bioethanol production}

\author{
Vázquez Zeballos, Sylvia Enid ${ }^{(1)}$, Buxedas, Luciana ${ }^{(1)}$, Lopretti, Mary ${ }^{(1,2)}$ \\ (1) Laboratorio de Bioquímica y Biotecnología, Centro de Investigaciones Nucleares, Facultad de Ciencias, Uruguay \\ (2) Departamento de Biotecnología y Bioprocesos, Laboratorio Tecnológico del Uruguay, Uruguay \\ Contacto: sylvia.vazquez.zeballos@gmail.com \\ Recibido: 15/6/2012 - Aprobado: 16/11/2012
}

\section{Resumen}

Con el objetivo de obtener nuevas cepas de levadura capaces de resistir condiciones rigurosas de cultivo se sometió un cultivo fresco de Saccharomyces cerevisiae M522 a Y-irradiación. Se generó una colección de cepas y se evaluó su capacidad de crecimiento a elevadas concentraciones de azúcar y etanol. Se seleccionó una de las cepas y se estudió en ella el efecto de los productos de degradación de la lignina, oligómeros fenólicos metoxilados obtenidos de su despolimerización oxidativa por tratamiento biológico. Se estudiaron también las enzimas involucradas. Todos los cultivos fueron evaluados por absorbancia a $660 \mathrm{~nm}$ tras 24 horas de incubación a $37^{\circ} \mathrm{C}$. En cuanto a las fracciones fenólicas, se obtuvo el perfil por espectrofotometría UV y se identificaron enzimas laccasa, desmetilasa y lig-peroxidasa. Se obtuvo una cepa (SacSV-10) con las mismas características de cultivo que la M522 en YPD. Se logró cultivar la cepa en un caldo con $10 \%$ de etanol, cepa que toleró el efecto de los productos de degradación de la lignina, así como una concentración de glucosa de $40 \mathrm{~g} / \mathrm{L}$, y en condiciones anaerobias se obtuvo una biomasa mayor que para la M522. En conclusión, SacSV-10 es un prometedor candidato para usar en producciones de alcohol a partir de residuos lignocelulósicos.

Palabras clave: Levaduras, extremófilos, biocombustibles, lignina.

\begin{abstract}
$\underline{\text { Abstract }}$
In order to obtain new strains of yeast capable to resist rigorous culture conditions, a fresh culture of Saccharomyces cerevisiae M522 was submitted to Y-radiation. The result was a collection of strains whose capacity to tolerate elevated sugar and ethanol concentrations were tested. One of those strains was selected to analyze the effect on the culture of products of lignin degradation, the methoxylated phenolic oligomers obtained from its oxidative depolymerization by biological treatment. The enzymes involved were also studied. Spectrophotometer determinations were done at $660 \mathrm{~nm}$ to assess all cultures after 24 hours of incubation at $37{ }^{\circ} \mathrm{C}$. It was possible to obtain the profile of the phenolic fraction by $\mathrm{UV}$ spectrophotometry and Laccase, Demetilase and Lig-peroxidase enzymes were identified. A strain which was called SacSV-10 was obtained with the same characteristics of the M522 in YPD. The strain was cultivated in a broth with $10 \%$ ethanol concentration and it tolerated the effect of products of lignin degradation as well as a glucose concentration of $40 \mathrm{~g} / \mathrm{L}$, and a biomass in anaerobic conditions greater than the M522 was obtained. In conclusion, SacSV-10 is a promising candidate to be used in alcohol production from sources as lignocellulose residues.

Keywords: Yeast, extremophiles, biofuels, lignin.
\end{abstract}

\section{Introducción}

La industria forestal produce toneladas de desechos anuales de residuos lignocelulósicos que constituyen un importante problema de contaminación. La capacidad de producir bioetanol a partir de ellos en procesos rentables con aceptables tasas de producción sigue siendo un desafío para la comunidad científica (Fernández et al., 2011; Cuervo et al., 2009; Carreón et al., 2009; Sánchez et al., 2005).

Existen muchos puntos críticos en este bioproceso, uno de ellos es el tratamiento que se debe realizar a la lignina previo a la fermentación, debido a que la lignina constituye una barrera para acceder a la celulosa. Esto se puede lograr por tratamientos físicos, químicos o biológicos. Los pretratamientos dejan en el medio trazas de lignina y productos de su despolimerización, oligómeros fenólicos metoxilados que pueden afectar de manera significativa la viabilidad y el comportamiento de los microorganismos responsables de la fermentación (Cuervo et al., 2009; Mariscal, 2011; Pérez et al., 2002).

Luego del pretratamiento es preciso instrumentar un proceso de sacarificación en el cual enzimas celulasas y laccasas, entre otras, producidas por hongos con temperaturas óptimas de acción que rondan los $50{ }^{\circ} \mathrm{C}$, despolimerizan la celulosa proporcionando altas concentraciones de glucosa libre en el medio, que puede ser metabolizada por microrganismos en procesos anaerobios con producción de etanol (Fernández et al., 2011; Yu et al., 2003; Pérez et al., 2002).

El punto de enfoque más importante podría ser encontrar cepas capaces de resistir condiciones extremas de cultivo (Mariscal, 2011). $\mathrm{Si}$ las cepas pueden ser cultivadas a temperaturas entre $37^{\circ} \mathrm{C}$ y $45^{\circ} \mathrm{C}$, se denominan termotolerantes, y termófilas a temperaturas superiores, lo cual posibilita considerar procesos de sacarificación y fermentación 
simultáneos. Estos modos de operación presentan dos ventajas: menos tiempo de uso del reactor y menor exposición de los microrganismos que se utilizan para la fermentación a tan altas concentraciones de azúcar, ya que ellos mismos la van consumiendo (Mejía et al., 2009). Otro factor a tener en cuenta es la concentración de alcohol remanente en el fermentador, que puede afectar la viabilidad de los microorganismos (Mariscal, 2011).

Saccharomyces cerevisiae es una levadura corrientemente utilizada en procesos de producción de bioetanol en la industria (Valdivieso, 2006). Las cepas se pueden modificar por medio de técnicas de biología molecular introduciendo mutaciones específicas o por inducción con agentes como la $\gamma$-irradiación, que provoca mutaciones al azar en el genoma de la levadura (Vinci et al., 1999; Valdivieso, 2006).

El objetivo de este trabajo es obtener nuevas cepas de levadura, capaces de resistir condiciones rigurosas de cultivo, con fines a la producción de bioetanol.

\section{Materiales y Métodos}

\section{Generación de mutantes}

Se irradiaron durante diferentes tiempos cultivos de la levadura Saccharomyces cerevisiae M522 (ATCC) en un Gammacell (Gamma Chamber 4000 a Isotope group, Bhabha Atomic Research Center, Trombay, Bombay, India), y se determinó la dosis letal 50. Luego se irradió durante ese tiempo un cultivo fresco de la levadura en caldo YPD (20 g/L de glucosa BENZO, $10 \mathrm{~g} / \mathrm{L}$ de extracto de levadura BACTO, $10 \mathrm{~g} / \mathrm{L}$ de peptona bacteriológica OXOID, solución buffer Mc. Laine pH 4.5) (Suresh et al., 1999). A partir del tubo irradiado se realizaron diluciones seriadas que se sembraron por triplicado en placas de YPD agar a los efectos de obtener colonias aisladas. Se sembró en paralelo la cepa M522 como control. De las placas que contenían colonias aisladas se seleccionaron por morfología y aspecto (color, textura, etcétera) 10 colonias que se transfirieron a tubos con $2 \mathrm{ml}$ de YPD para generar cultivos puros de las nuevas cepas de Saccharomyces spp, que se denominaron SacSV-n ( $\mathrm{n}=$ número correspondiente a su aislamiento). Las cepas fueron mantenidas en placa de YPD en heladera y se congelaron a $-20{ }^{\circ} \mathrm{C}$ en leche.

\section{Estudio de condiciones metabólicas de los mutantes}

A partir de una placa de mantenimiento en YPD de cada cepa y de la levadura M522 mantenidas en heladera, se llevaron tubos con $3 \mathrm{ml}$ de suero fisiológico $\left(\mathrm{NaCl} 0,9 \%\right.$ ) a una concentración de $1.5 \mathrm{e}^{8}$ utilizando la escala de Mac Farland. Se transfirieron $150 \mu \mathrm{L}$ a tubos con $9 \mathrm{ml}$ de YPD, YPD $40 \mathrm{~g} / \mathrm{L}$ de glucosa e YPD complementado con $10 \%$ de alcohol.

Los tubos se incubaron durante 24 horas en condiciones aerobias, sin agitación, a $37{ }^{\circ} \mathrm{C}$ y a $50{ }^{\circ} \mathrm{C}$ (los que correspondían al ensayo de temperatura extrema). Los cultivos se evaluaron por medidas de absorbancia a $660 \mathrm{~nm}$ (Thermo scientific. Mod. Evolution $160 \mathrm{UV}$ Vis), utilizando como blanco en cada caso el medio sin inocular.

\section{Tolerancia de la cepa SacSV-10 a los productos de degradación de la lignina}

Se seleccionó una de las cepas SacSV-10 y se estudió el efecto sobre el cultivo de los productos de degradación de la lignina, los oligómeros fenólicos metoxilados que se obtuvieron mediante su despolimerización oxidativa por tratamiento biológico a una concentración de fenoles de $0,80 \mathrm{~g} / \mathrm{l}$. Se realizaron cultivos de la cepa seleccionada en medio YPD previamente inoculado con el extracto de lignina tratado enzimáticamente a una concentración del $0,5 \%$, tanto para el lixiviado superficial como para el lixiviado decantado, con el objetivo de estudiar los efectos de los residuos de lignina de diferentes pesos moleculares. Se utilizó como control un cultivo realizado en medio YPD sin lignina. Todos los cultivos se incubaron a $35{ }^{\circ} \mathrm{C}$ y se evaluaron determinando la absorbancia a $660 \mathrm{~nm}$ durante 8 horas. Se realizaron dos ensayos independientes por triplicado.

\section{Tratamiento de modificación de lignina}

Con el fin de obtener monómeros y oligómeros de lignina solubilizados por despolimerización, se trataron $100 \mathrm{ml}$ de medio de cultivo que contenía $10 \mathrm{~g} / 1$ de glucosa, $0,2 \mathrm{~g} / 1$ de extracto de levadura, $0,5 \mathrm{~g} / 1$ de tartrato de amonio, $1 \mathrm{ml}$ de solución de sales de Kirk (Kirk et al., 1978) y $10 \mathrm{ml}$ de lignina Kraft a pH 5. El medio se esterilizó durante 15 minutos a $121^{\circ} \mathrm{C}$ y se inoculó con $5 \mathrm{ml}$ de cultivos previos de los hongos Gloeophyllum trabeum y Phanerochaete chrysosporium.

Cada cultivo se mantuvo a $37{ }^{\circ} \mathrm{C}$ durante 6 días y se analizaron las actividades enzimáticas presentes en el sobrenadante según la metodología utilizada por Lopretti et al. (2010).

Posteriormente, se realizó una despolimerización oxidativa de la lignina ( $200 \mathrm{ml}$ de solución que contenía 50 g de madera de Eucaliptus grandis con $25 \%$ de lignina) con los extractos enzimáticos obtenidos (50 $\mathrm{ml}$ de extracto enzimático). La reacción se llevó a cabo en un sistema agitado a $37{ }^{\circ} \mathrm{C}$ durante 15 días. Luego se bajó el pH de la solución a 4.00 con $\mathrm{HCl} 0.1 \mathrm{M}$ para precipitar el polímero, y se analizó el sobrenadante.

\section{Análisis de las fracciones fenólicas}

Se determinó el perfil de las fracciones fenólicas por espectrofotometría UV (Thermo scientific. Mod. Evolution 160 UV Vis) realizando un barrido de longitudes de onda entre $200 \mathrm{~nm}$ y $70 \overline{0}$ nm. (Tien Ming, 1988; Lopretti et al., 1998).

\section{Resultados y Discusión}

\section{Estudio de condiciones metabólicas de los mutantes}

En la Figura 1 se presentan los resultados del estudio metabólico de las cepas mutantes de Saccharomyces cerevisiae M522 y de la cepa original. Las cepas 4 y 9 no presentaron crecimiento adecuado en ninguna de las condiciones ensayadas, lo que hace suponer que las mutaciones introducidas en su genoma provocaron cambios que afectaron su viabilidad. Con respecto a la capacidad de crecimiento en un medio como el YPD, medio óptimo para las levaduras, los demás mutantes presentaron un crecimiento adecuado; las cepas SacSV-8 y SacSV-10 (Figura 2) mostraron un comportamiento más parecido al de M522. Cuando el medio YPD fue complementado con glucosa a una concentración de $40 \mathrm{~g} / \mathrm{L}$, las cepas SacSV-5, 6, 7, 8 y 10 se comportaron mejor que la M522, con una mayor proliferación en el medio YPD. Con respecto a los ensayos de temperatura extrema todas las cepas evidenciaron muy poco crecimiento. Al complementar el medio con $10 \%$ de alcohol la cepa M522 mostró la mejor respuesta, y fue similar, aunque menor, la observada para las cepas SacSV-10 y 3 . 


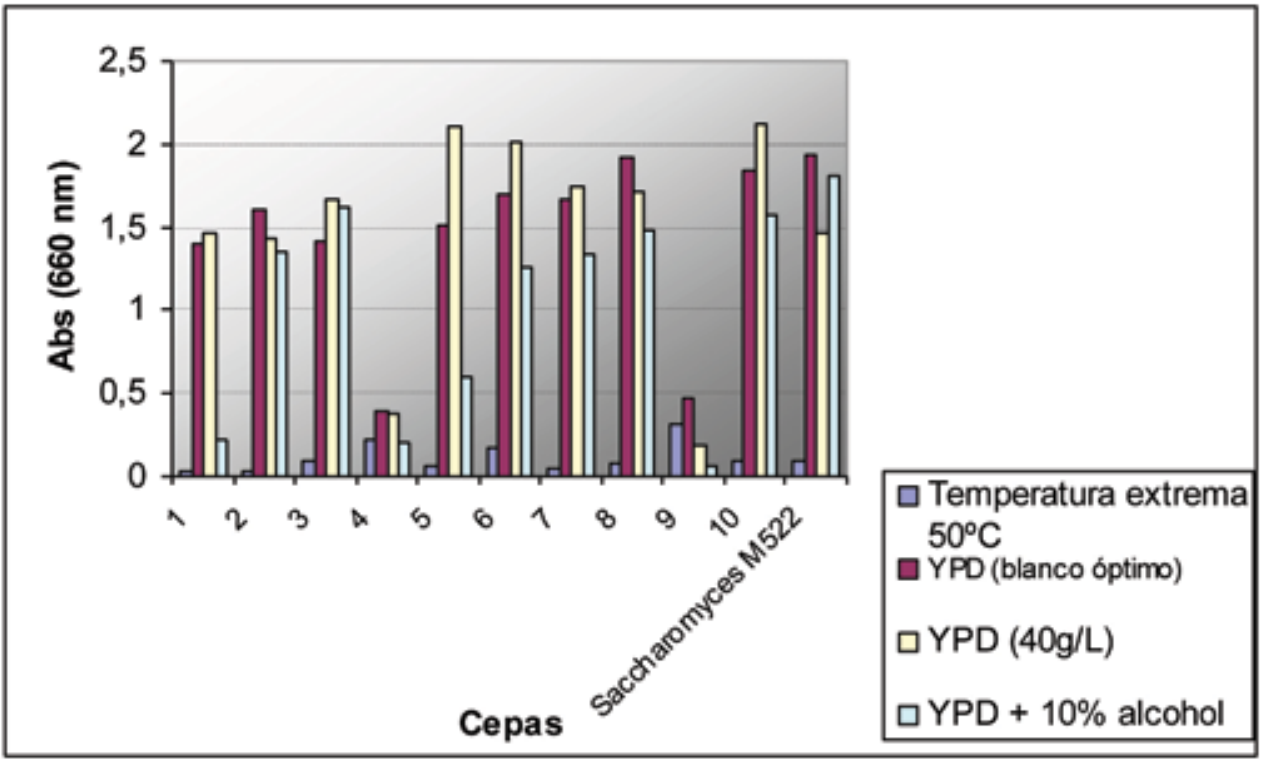

Figura 1. Comportamientos de la cepa Saccharomyces cerevisiae M522 y de la colección de mutantes en las diferentes condiciones metabólicas ensayadas.
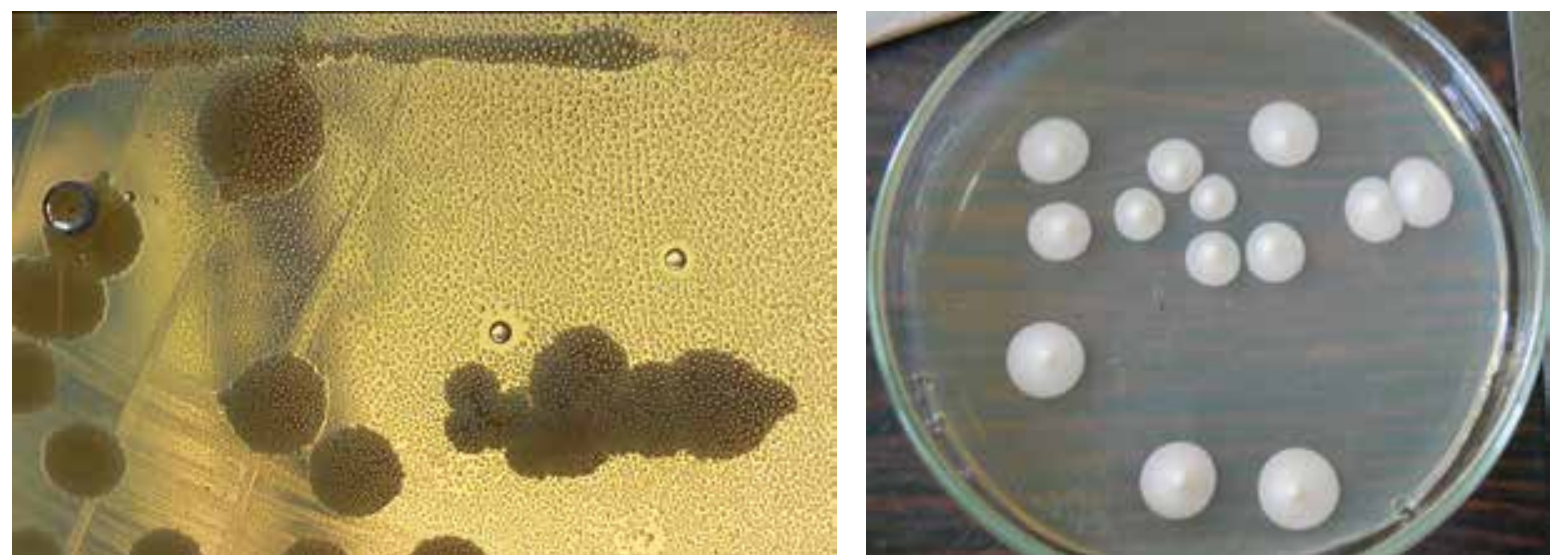

Figura 2. Saccharomyces cerevisiae spp. SacSV-10 obtenida por Y-irradiación.

\section{Tolerancia de la cepa SacSV-10 a los productos de degradación de la lignina}

La cepa SacSV-10 se comportó de manera similar en los medios complementados con los productos de degradación de la lignina de diferentes pesos moleculares (lixiviado decantado y lixiviado superficial) y en el medio sin lignina (Figura 3). En todos los casos el cultivo alcanzó la fase de mantenimiento a las cuatro horas de tratamiento con una concentración de 10e7. Según estos resultados, no se observa un efecto significativo de los productos de degradación de la lignina sobre la levadura en las condiciones ensayadas.

\section{Tratamiento de modificación de la lignina}

Los resultados de los ensayos de actividad evidencian la presencia de tres enzimas lignina peroxidasa, laccasa y desmetilasa. Con respecto a las actividades, la lignina peroxidasa presentó mayor actividad 108 $\mathrm{UE} / \mathrm{ml}$, seguida de laccasa con $85 \mathrm{UE} / \mathrm{ml}$ y la desmetilasa con $64 \mathrm{UE} /$ $\mathrm{ml}$.

\section{Análisis de las fracciones fenólicas}

El tratamiento con $G$. trabeum y $P$. chrysosporiumin oxidó y despolimerizó la lignina, y se obtuvieron productos con absorbancias que se muestran en la Tabla 1. Pueden observarse los picos a 310 $\mathrm{nm}$ y $354 \mathrm{~nm}$ que aparecen luego del tratamiento biológico: estos corresponden al aldehído veratrílico $(310 \mathrm{~nm})$ y al ácido veratrílico (354 nm), los cuales son monómeros de la degradación de lignina (Tien Ming, 1988; Lopretti et al., 1998). 


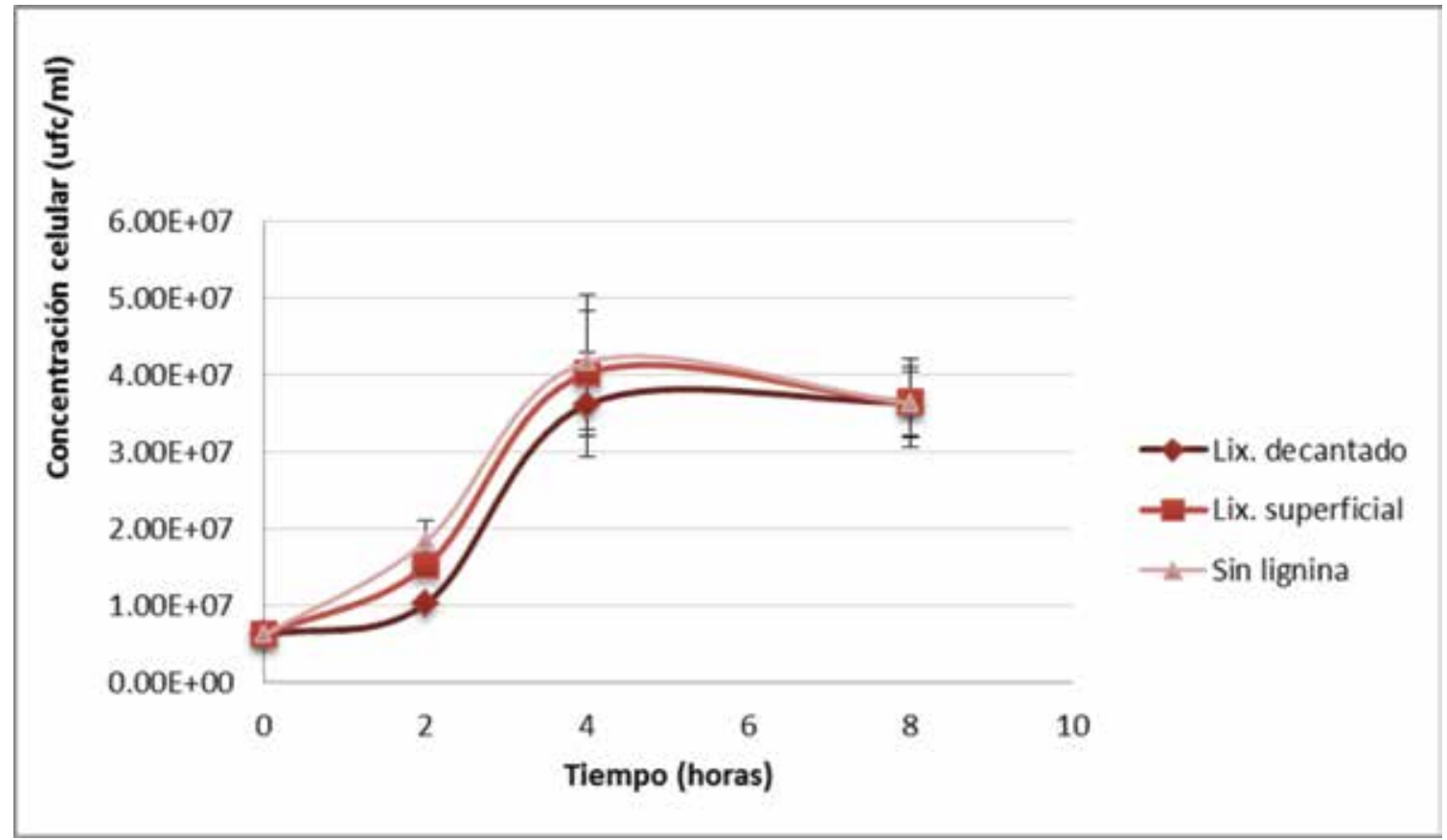

Figura 3. Curvas de crecimiento en los diferentes medios complementados con los productos de degradación de la lignina de diferentes pesos moleculares.

\begin{tabular}{|c|c|c|}
\hline \multirow{2}{*}{ Tratamiento } & Longitudes de onda $(\mathbf{n m})$ & Intensidad del pico \\
\hline Lignina sin tratamiento & 280 & 0.670 \\
\cline { 2 - 3 } & 310 & 0.008 \\
\cline { 2 - 3 } & 354 & --- \\
\hline \multirow{2}{*}{ Ligninas con tratamiento } & 280 & 0.235 \\
\cline { 2 - 3 } & 310 & 0.210 \\
\cline { 2 - 3 } & 354 & 0.125 \\
\hline
\end{tabular}

Tabla 1. Análisis por espectrofotometría de la lignina pre y post tratamiento.

\section{Conclusiones}

Los resultados de los ensayos en el medio complementado con glucosa $40 \mathrm{~g} / \mathrm{L}$ sugieren que las levaduras mutantes y la M522 no sufren saturación por sustrato a estas concentraciones. En ensayos futuros se deberán evaluar concentraciones de glucosa superiores y la capacidad de crecimiento con otros azúcares como fuente de carbono, por ejemplo, xilosa.

La temperatura ensayada de $50^{\circ} \mathrm{C}$ afectó de manera significativa el desarrollo de todas las cepas estudiadas. En ensayos futuros se deberán evaluar temperaturas intermedias entre la óptima y la seleccionada a efectos de determinar la máxima temperatura a la cual se podría realizar el cultivo para los ensayos de sacarificación y fermentación en simultáneo, con el objetivo de trabajar a una temperatura próxima a la óptima de actividad de las enzimas celulasas.

En las fracciones fenólicas se identificaron enzimas laccasa, desmetilasa y lig-peroxidasa que fueron las responsables de la producción de monómeros fenólicos de lignina que aparecen en procesos de hidrólisis para obtención de azúcares fermentables y que actúan generalmente como inhibidores del crecimiento de las levaduras tradicionales.

Se obtuvo una cepa (SacSV-10) con las mismas características de cultivo que la M522 en YPD. Se logró cultivar la cepa en un caldo con 10 $\%$ de etanol, que toleró el efecto de los productos de degradación de la lignina, así como una concentración de glucosa de 40 g/L, y se obtuvo en condiciones anaerobias una biomasa mayor que para la M522.

En conclusión, SacSV-10 es un prometedor candidato para usar en producciones de alcohol a partir de residuos lignocelulósicos. 


\section{Referencias}

- CARREÓN, O.; RAMOS, A.; CENTENO, S.; LEAL, L.; MARTÍNEZ, A.; FERNÁNDEZ, M. Etanol Carburante. En: BioTecnología. 2009, 13(3):79-102.

- CUERVO, C.; FOLCK, J.; QUIROZ, R. Lignocelulosa como fuente de azúcares para la producción de etanol. En: BioTecnología. 2009, 13(3):11-25.

- FERNÁNDEZ, J.; LUCAS, H.; BALLESTEROS, M. Energías renovables para todos: biocarburantes. Madrid: Haya Comunicación, 2011.

- KIRK, T.; SCHULTZ, E.; CONNORS, W.; LORENZ, L.; ZEIKUS, J. Influenze of culture parameters on lignin metabolism by Phanerochaete chrysosporium. En: Archives of Microbiology. 1978, 117:227-235.

- LOPRETTI, M. Technical feasibility to produce modified phenols from lignocellulosic materials. En: EUBC\&E. 2010, 1519-1521.

- LOPRETTI, M.; CABELLA, D.; MORAIS, J.; RODRIGUES, A. Demethoxylation of lignin-model compounds with enzyme extracts from Gloeophilum trabeum. En: Process Biochemistry. 1998, 33:657-66.

- MARISCAL, J. Evaluación y selección de microorganismos para la producción de etanol a nivel industrial. Bogotá: Universidad Nacional de Colombia, Colombia, 2011.

- MEJÍA, L.; ALBÁN, D.; MURCIA, N.; CUERVO, R.; DURÁN, J. Hidrólisis y fermentación alcohólica simultánea (HFS) del residuo agroindustrial del mango común (Mangifera indica L) utilizando levaduras Saccharomyces cerevisiae spp y cepa recombinante $\mathrm{RH}$ 218. En: Revista Cientifica Guillermo de Ockham. 2009, 7(2):5164.

- PÉREZ, J.; MUÑOZ-DORADO, A.; DE LA RUBIA, T.; MARTINEZ, E. Biodegradation and biological treatments of cellulose, hemicellulose and lignin: an overview. En: Int. Microbiol. 2002, 5:53-62.

- SÁNCHEZ, O.; CARDONA, C. Producción biotecnológica de alcohol carburante I: obtención a partir de diferentes materias primas. En: INCI. 2005, 30(11):671-678.

- SURESH, K.; KIRAN, N.; VENKATESWER, L. Utilization of damaged sorghum and rice grains for ethanol production by simultaneous saccharification and fermentation. En: Bioresource Technology. 1999, 68:301-304.

- TIEN MING, K. Lignin peroxidase of phanerochaete chrysosporium. En: Methods in Enzymology. 1988, 238-249.

- VALDIVIESO, M. Obtención y caracterización de cepas de Saccharomyces cerevisiae productoras de glutatión. Granada: Universidad de Granada, España, 2006.

- VINCI, V.A.; BANG, G. Manual of industrial microbiology and biotechnology. ASM: Washington, 1999. pp.103-113.

- YU, Z.; ZHANG, H. Pretreatment of cellulose pyrolysate for ethanol production by Saccharomyces cerevisiae, Pichia sp. YZ1 and Zymomonas mobile. En: Biomass Bioenerg. 2003, 24:257-263. 